\title{
Identificación de microorganismos presentes en la atmósfera baja de una zona industrial del área metropolitana de Monterrey
}

\author{
Delia F. Verástegui Rubioa , Juan M. Contreras Lópeza, Yessica Y. Narváez Torresa , Debnhi Y. Garza \\ Villarreal $^{\mathrm{a}}$, Ma. Elena Cantú Cárdenas ${ }^{\mathrm{a}}$, Xristo Zárate ${ }^{\mathrm{a}}$, Carmen Ponce Caballerob ${ }^{\mathrm{b}}$ y Evangelina \\ Ramírez Lara ${ }^{\mathrm{a} *}$ \\ ${ }^{a}$ Universidad Autónoma de Nuevo León, Facultad de Ciencias Químicas, Av. Universidad s/n, Cd. Universitaria, San Nicolás de los \\ Garza Nuevo León, C.P. 66451, México. \\ ${ }^{b}$ Universidad Autónoma de Yucatán, Facultad de Ingeniería, Av. de Industrias No Contaminantes s/n, Mérida, Yucatán, C.P. 97310, \\ México \\ *E-mail: evangelina.ramirezlr@uanl.edu.mx
}

Recibido 23 de febrero 2015, Aceptado 11 de junio 2015

\section{Resumen}

Los microorganismos son una causa importante de enfermedades y alergias transmitidas por aire, en áreas urbanas la contaminación por partículas suele agravar este fenómeno al ser un vehículo de transporte para estos microorganismos. A partir de muestras del aire ambiente del municipio de San Nicolás de los Garza, en el estado de Nuevo León, hemos identificado una variedad considerable de géneros de hongos entre los cuales se encuentran especies causantes de alergias y otras patologías como Cladosporium y Chaetomium. Además se aislaron e identificaron varias bacterias, entre ellas Enterobacter agglomerans y Pseudomonas aeuroginosa, patógenas para los humanos.

Palabras clave: identificación de microorganismos, atmósfera baja, Bacillus, Enterobacter, Monosporium.

\section{Introducción}

Algunos microorganismos presentes en el aire son un riesgo potencial para la salud, por ejemplo enfermedades como la amigdalitis y meningitis son causadas por Streptococcus pyogenes y Haemophilus influenzae respectivamente [1].

La atmósfera baja también conocida como tropósfera, se encuentra localizada entre los 0 y $12 \mathrm{~km}$ de altitud, no tiene una especie de microorganismo específico, pero es un medio para la dispersión de muchos de ellos (esporas, bacterias, virus, hongos), debido a las fuerzas de fricción causadas entre el aire y la superficie de la tierra y aunado al perfil de temperaturas, desempeñan un papel importante en la dinámica de las masas de aire y en los procesos de mezcla de contaminantes. La presencia de uno u otro tipo de especies depende del origen, de la dirección e intensidad de las corrientes de aire y de la supervivencia del microorganismo; algunos de ellos se encuentran en forma esporulada, éstas sobreviven mejor en la atmósfera baja porque soportan la desecación [2].

La contaminación atmosférica por partículas en el área metropolitana de Monterrey es un problema, por lo que la población está expuesta continuamente tanto a contaminantes de origen químico como a microorganismos los cuales pueden causarle enfermedades. Estudios realizados en distintos países han identificado qué tipo de microorganismos han sido encontrados en la atmósfera baja; por ejemplo en la ciudad de Bogotá, Colombia, se realizó un muestreo con el equipo MS-100 para aspirar aire de diversos puntos de la ciudad; mostraron que Bacillus subtilis, Bacillus cereus, Micrococcus oeteus y Staphylococcus xylosus eran las bacterias más abundantes [3]. Mientras que en la ciudad de México, se identificaron las bacterias Bacillus pumilus, B. safensis, B. megaterium, B. subtilis, B. anthracis y algunas bacterias que no forman esporas como Enterococcus spp, Staphylococcus epidermidis, $S$. saprophyticus, y S. pseudintem [4]. Sobre la presencia de hongos, un estudio en la atmósfera baja en Ecuador mostró las especies Cladosporum y Penicillum en su mayoría, y en menos cantidades Rhizopus spp, Cephalosporium spp y Aspergillus spp [5].

Este tipo de estudios permiten modificar estrategias en el manejo de plagas, enfermedades y alergias, lo cual ayuda a mejorar la salud pública y la productividad agrícola [2]. Es importante hacer conciencia de prevención y control de la contaminación del aire de manera que se impulse a mejorar la calidad del aire en el corto y largo plazo y así alcanzar niveles de calidad del aire satisfactorios.

En este trabajo se identificaron los microorganismos encontrados en muestras de partículas suspendidas en el aire de una zona en el municipio industrial de San Nicolás de los Garza, Nuevo León, donde se registró la presencia de una amplia diversidad de hongos y bacterias, algunos de ellos patógenos como el género Salmonella. 


\section{Parte experimental}

Para el análisis de los microorganismos se utilizó un muestreador de partículas viables de aluminio de dos etapas de la marca New Star Environmental Inc., imagen del instrumento en la figura 1. Para el muestreo, se enciende la aspiradora del muestreador y se mantiene a una velocidad de flujo 1 ACFM (28.31/min) de aire. Los muestreos se hicieron dos veces por semana, en cada día un muestreo por la mañana y otro por la tarde, durante 6 semanas en la primavera del 2014. Los tiempos de muestreo fueron de 30 minutos utilizando placas con dos diferentes medios de cultivo: papa-dextrosa-agar (PDA) y agar nutritivo para la identificación de hongos y bacterias respectivamente. Para el aislamiento de los hongos se llevó a cabo la técnica de inoculación y transferencia y su posterior resiembra en placa por rasgadura; y para observar las características microscópicas realizamos un montaje en azul de lactofenol y siembra en microcultivo [6]. En la identificación de las bacterias, se utilizó la tinción Gram para observar las características microscópicas de las colonias y poder aislarlas para obtener un cultivo puro. El aislamiento de las bacterias se llevó a cabo mediante la técnica de la estría cruzada para separar colonias. Una vez obtenido un cultivo puro, éste se inocula en caldo nutritivo para su crecimiento, para después realizar pruebas bioquímicas dependiendo de su morfología y su tinción de Gram. Las pruebas realizadas para Bacilos Gram positivos fueron: producción de amilasas; fermentación u oxidación de lactosa; producción de catalasa y producción de indol, sulfuro y motilidad (SIM). Para los Bacilos Gram negativos se realizaron las pruebas de fermentación de lactosa; producción de indol, sulfuro y motilidad en medio SIM; prueba de rojo de metilo y Voges Proskauer; utilización de citratos; descarboxilación de lisina y producción de sulfuro; fermentación de carbohidratos, producción de sulfuro y gas en medio azúcar triple y hierro (TSI) y producción de gelatinasa. Las pruebas realizadas para los Cocos Gram positivos fueron: producción de pigmento en el medio selectivo para estafilococos $\mathrm{S} 110$; producción de coagulasa; producción de catalasa y producción de gelatinasa [6].

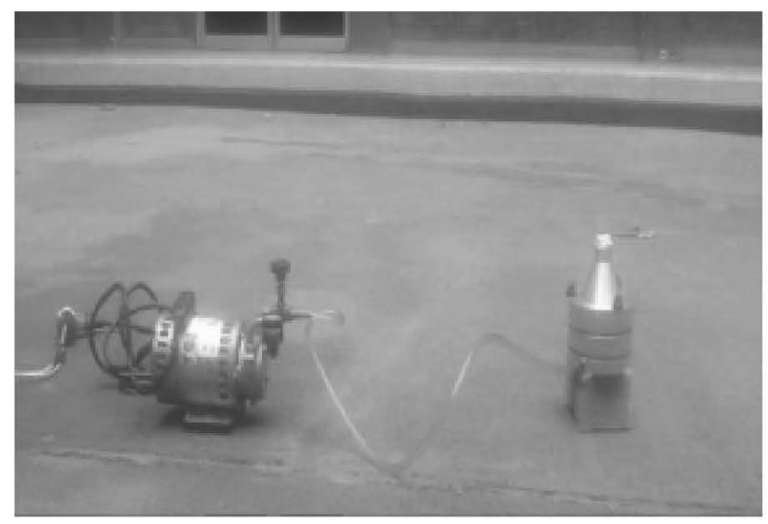

Figura 1. Fotografía del muestreador de partículas viables de aluminio de dos etapas de la marca New Star Environmental Inc. El instrumento estuvo ubicado en la azotea de la Facultad de Ciencias Químicas de la UANL en San Nicolás de los Garza, N.L.

\section{Resultados y discusión}

En la figura 2 se puede observar el crecimiento de hongos en una placa de PDA después de la incubación con la muestra del aire.

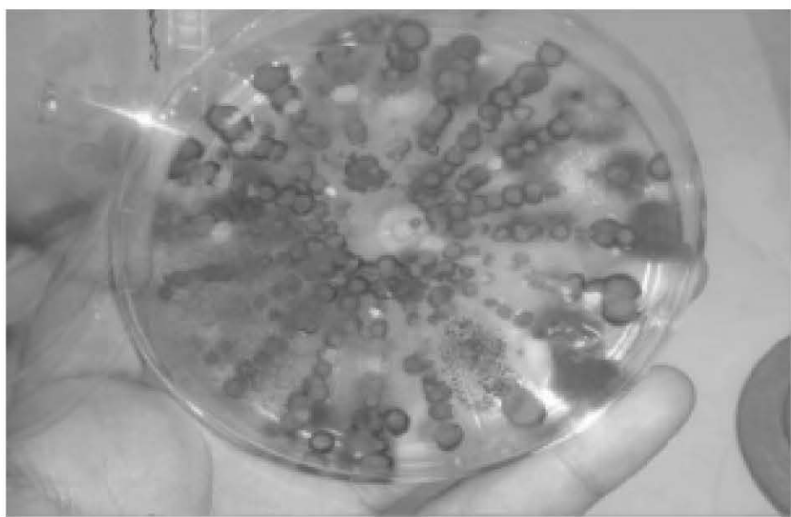

Figura 2. Cultivo mixto de hongos en placa de PDA posterior a la incubación con muestras de aire.

Claramente se puede observar una mezcla de hongos distintos, los cuales fueron aislados hasta obtener cultivos puros; la figura 3 muestra uno de éstos, así como su micrografía correspondiente para ser identificado como género Monosporium spp.
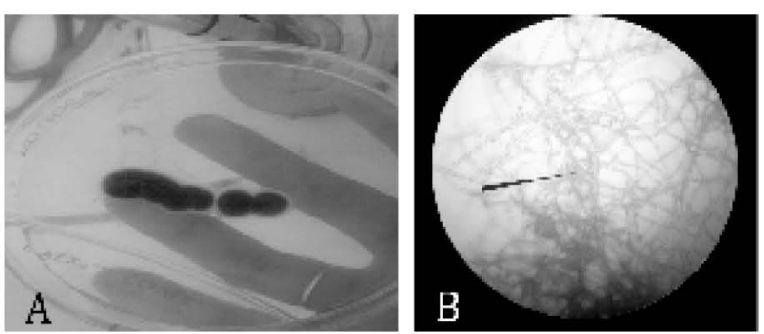

Figura 3. A. Cultivo puro del hongo Monosporium spp. obtenido a partir de las placas de muestreo con PDA. B. Micrografía óptica, observación en $10 \mathrm{X}$

También mediante las características macroscópicas en Agar PDA y las características microscópicas de los hongos en cultivo puro se identificaron los siguientes géneros: Aspergillus, Rizhopus, Cladosporium, Bipolaris, Monilia, Curvularia, Chaetomimum, Fusarium y Cephalosporium.

En la figura 4 se muestran las características microscópicas de algunos de ellos. 

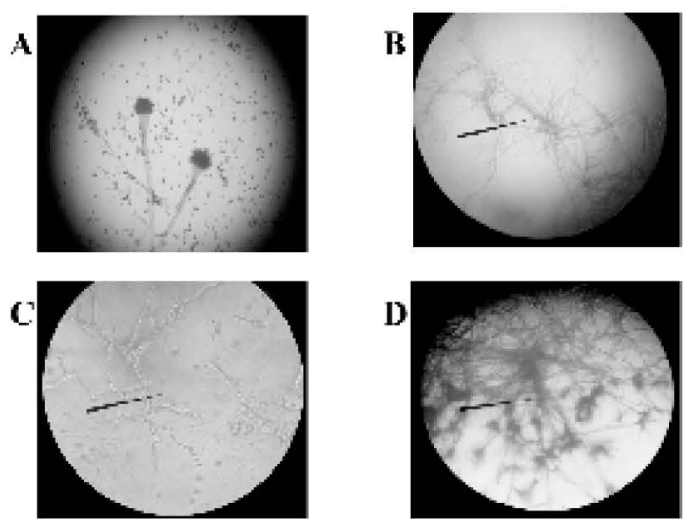

$\mathbf{F}$
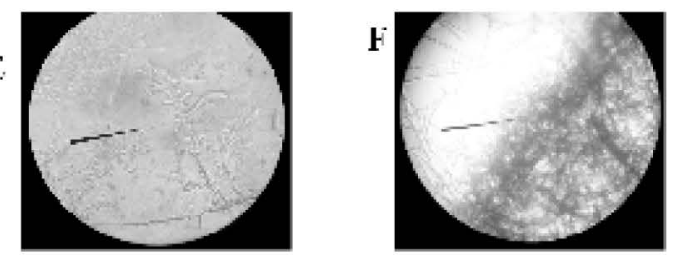

Figura 4. Micrografias de los hongos aislados de cultivos mixtos de placas PDA que corresponden a los géneros: A. Aspergillus, B. Rizhopus, C. Cladosporium, D. Monilia, E. Fusarium, F. Cephalosporium.

Se observaron algunas especies de hongos que no se reportaron en los antecedentes consultados, esto puede ser debido a las condiciones climáticas que se presentaron durante el periodo de muestreo que favorecieron el crecimiento. La especies de hongos que más se encontraron en las diferentes placas incubadas con las muestras de aire fueron Monosporium spp, seguido por Bipolaris spp, Trichophyton spp, Curvularia spp y Aspergillus spp. Estos resultados nos indican que hay una moderada contaminación y carga microbiana por la diversidad de especies presentes en el ambiente, lo que se puede asociar a ciertas enfermedades respiratorias, alergias, etc. Por ejemplo, Aspergillus puede provocar sinusitis alérgica y onicomicosis [7]; mientras que Fusarium también causa queratitis, una infección en los ojos [8].

Con respecto a las bacterias identificadas, la tabla 1 presenta las pruebas morfológicas de los cultivos puros que se lograron aislar de las placas de agar nutritivo utilizadas directamente con el muestreador de partículas. La tabla también muestra la descripción de las colonias, así como su resultado tras la tinción de Gram.
Tabla 1. Características de las especies de bacterias encontradas en placas de agar nutritivo.

\begin{tabular}{|c|c|c|}
\hline $\begin{array}{l}\text { Cultivo/ } \\
\text { Muestra }\end{array}$ & Tipo de crecimiento & $\begin{array}{c}\text { Observación } \\
\text { microscópica }\end{array}$ \\
\hline 1 & $\begin{array}{l}\text { Colonias amarillas, } \\
\text { brillantes de aspecto } \\
\text { húmedo, abultadas. }\end{array}$ & $\begin{array}{l}\text { Cocos Gram positivos, en } \\
\text { racimo, algunos aislados. }\end{array}$ \\
\hline 2 & $\begin{array}{l}\text { Colonias amarillas, } \\
\text { planas, de aspecto seco, } \\
\text { delgadas, muy pequeñas. }\end{array}$ & $\begin{array}{l}\text { Bacilos Gram negativos, } \\
\text { largos. }\end{array}$ \\
\hline 3 & $\begin{array}{l}\text { Colonias blancas, planas, } \\
\text { de aspecto seco y de } \\
\text { forma cristalizada. }\end{array}$ & $\begin{array}{l}\text { Bacilos Gram negativos, } \\
\text { cortos. }\end{array}$ \\
\hline 4 & $\begin{array}{l}\text { Colonias blancas, planas, } \\
\text { agrupadas como racimos } \\
\text { de uvas, de aspecto } \\
\text { húmedo. }\end{array}$ & $\begin{array}{l}\text { Bacilos Gram negativos, } \\
\text { cortos, delgados, aislados. }\end{array}$ \\
\hline 5 & $\begin{array}{l}\text { Colonias blancas, } \\
\text { abultadas, de aspecto } \\
\text { húmedo. }\end{array}$ & $\begin{array}{l}\text { Bacilos Gram negativos, } \\
\text { en racimo. }\end{array}$ \\
\hline 6 & $\begin{array}{l}\text { Colonias blancas, planas, } \\
\text { de aspecto seco, con } \\
\text { forma irregular. }\end{array}$ & $\begin{array}{l}\text { Bacilos Gram positivos, } \\
\text { largos, delgados, no } \\
\text { agrupados. }\end{array}$ \\
\hline 7 & $\begin{array}{l}\text { Colonias blancas, planas, } \\
\text { pequeñas, de aspecto } \\
\text { húmedo/seco. }\end{array}$ & $\begin{array}{l}\text { Cocos Gram positivos, } \\
\text { agrupados y aislados. }\end{array}$ \\
\hline 8 & $\begin{array}{l}\text { Colonias amarillo pálido, } \\
\text { de aspecto húmedo, } \\
\text { circulares y planas. }\end{array}$ & $\begin{array}{l}\text { Bacilos Gram negativos, } \\
\text { largos, y algunos bacilos } \\
\text { cortos delgados. }\end{array}$ \\
\hline
\end{tabular}

Respecto a las pruebas bioquímicas, los Cocos Gram positivos 1 y 7 no se lograron identificar. Para las bacterias Gram negativas, la tabla 2 muestra los resultados de las pruebas, pudiendo identificar así al cultivo 2 como Enterobacter agglomerans, el cultivo $\mathbf{3}$ del género Salmonella spp., mientras que para el cultivo 4 corresponde al género Klebsiella spp., al cultivo 5 se le identificó como Pseudomonas aeuroginosa, y el cultivo 8 como Enterobacter aerogenes.

Se han encontrado infecciones nosocomiales causadas por las bacterias Klebsiella pneumoniae y Enterobacter aerogenes que han desarrollado resistencia a diversos antibióticos $[9,10]$. La salmonelosis, causada por Salmonella, es una infección bacteriana muy conocida que afecta el tracto intestinal, además es una enfermedad que carece de una prueba diagnóstica rápida, siendo todavía el cultivo el método estándar [11]. 
Tabla 2. Pruebas bioquímicas realizadas a las bacterias Gram negativas.

\begin{tabular}{|c|c|c|c|c|c|}
\hline Prueba & 2 & 3 & 4 & 5 & 8 \\
\hline $\begin{array}{l}\text { Fermentación de } \\
\text { lactosa }\end{array}$ & $(+)$ & $(-)$ & $(+)$ & $(-)$ & $(+)$ \\
\hline $\begin{array}{l}\text { Prueba de rojo de } \\
\text { metilo y Voges } \\
\text { Proskauer }\end{array}$ & $\begin{array}{l}(+) \text { en } \\
\text { rojo } \\
\\
(-) \text { en } \\
\text { Vogues }\end{array}$ & \begin{tabular}{|l}
$(-)$ en \\
rojo \\
\\
$(-)$ en \\
Vogues
\end{tabular} & $\begin{array}{l}(-) \text { en } \\
\text { rojo } \\
\\
(-) \text { en } \\
\text { Vogues }\end{array}$ & \begin{tabular}{|l}
$(+)$ en \\
rojo \\
\\
$(-)$ en \\
Vogues
\end{tabular} & $\begin{array}{l}(-) \text { en } \\
\text { rojo } \\
\\
(+) \text { en } \\
\text { Vogues }\end{array}$ \\
\hline $\begin{array}{l}\text { Producción de } \\
\text { indol, sulfuro y } \\
\text { motilidad en } \\
\text { medio SIM }\end{array}$ & $(-)$ & $(-)$ & $(-)$ & $(-)$ & $(+)$ \\
\hline Prueba de citratos & $(+)$ & $(-)$ & $(+)$ & $(+)$ & $(+)$ \\
\hline $\begin{array}{l}\text { Descarboxilación } \\
\text { de lisina y } \\
\text { producción de } \\
\text { sulfuro }\end{array}$ & $(-)$ & $(+)$ & $(+)$ & $(-)$ & $(+)$ \\
\hline $\begin{array}{l}\text { Fermentación de } \\
\text { carbohidratos y } \\
\text { producción de } \\
\text { sulfuro }\end{array}$ & $(-)$ & $(+)$ & $(-)$ & $(-)$ & $(-)$ \\
\hline $\begin{array}{l}\text { Producción de } \\
\text { gelatinasa }\end{array}$ & $(+)$ & $(+)$ & $(-)$ & $(+)$ & $(+)$ \\
\hline $\begin{array}{l}\text { Producción de } \\
\text { pigmentos en } \\
\text { caldo nutritivo }\end{array}$ & $(+)$ & $(-)$ & $(-)$ & $(-)$ & $(-)$ \\
\hline
\end{tabular}

La única bacteria Gram positiva identificada fue del género Bacillus spp. al dar positivas las pruebas de catalasa y amilasa y negativas las pruebas de fermentación, oxidación de lactosa y producción de indol, sulfuro y motilidad en medio SIM. Es común encontrar este tipo de bacteria ya que las endosporas fácilmente se encuentran en partículas resuspendidas en el aire [12].

\section{Conclusiones}

En el aire ambiente del municipio de San Nicolás de los Garza se aislaron e identificaron 11 especies de hongos entre los cuales se encuentran especies causantes de alergias y otras patologías. Se aislaron e identificaron 6 especies de bacterias, algunas de ellas son patógenas para el ser humano, además de oportunistas. Por lo tanto se encontró una diversidad considerable de especies durante el período de evaluación, contribuyendo así a las condiciones ambientales causantes de enfermedades respiratorias como resfriados, tos, etc.

\section{Referencias}

1. De la Rosa, M.C.; Mosso, M.A.; Ullan, C. El aire: hábitat y medio de transmisión de microorganismos.

Observatorio

Medioambiental 2002, 5, 375-402.

2. Alshareef, F.; Robson, G.D. Prevalence, persistence, and phenotypic variation of Aspergillus fumigatus in the outdoor environment in Manchester, UK, over a 2-year period. Med. Mycol. 2014, 52, 367-375.

3. Rodríguez, R.; Huertas, F. Evaluación de la contaminación del aire por microorganismos patógenos en bioaerosoles, en una zona de alta actividad industrial y flujo vehicular de la localidad de Puente Aranda en Botogá D.C. Universidad de la Salle, Facultad de Ingeniería Ambiental y Sanitaria, 2005.

4. García-Mena, J. Las bacterias aerotransportadoras de la región más transparente del aire. Instituto Politécnico Nacional, Centro de Investigaciones y Estudios Avanzados, 2010.

5. Granada, M.; Rivadeneira, D. Evaluación del efecto de la presencia de hongos en la calidad del aire como causa del síndrome del edificio enfermo en las edificaciones antiguas de la Pontificia Universidad Católica del Ecuador. Pontificia Universidad Católica del Ecuador, Escuela de Bioanálisis, 2011.

6. Baron, E.J.; Finegold, S.M. Diagnostic Microbiology: Textbook for the Isolation and Identification of Phatogenic Microorganisms. $8^{\mathrm{a}}$ edición, Mosby: 1990.

7. Pérez, J.E.; Cárdenas, C.; Hoyos, A.M Características clínicas, epidemiológicas y microbiológicas de la onicomicosis en un laboratorio de referencia, Manizales (Caldas), 2009. Infectio 2011, 168-176.

8. Vasantha, R.V.; Geraldine, P.; Kaliamurthy, J.; Jesudasan, C.A.; Thomas, P.A. Keratitis due to Fusarium langsethiae: Clinical profile, molecular identification, and susceptibility to antifungals. Mycopathologia 2015, 179, 453458.

9. Murphy, C.N.; Clegg, S. Klebsiella pneumoniae and type 3 fimbriae: nosocomial infection, regulation and biofilm formation. Future Microbiol. 2012, 7, 991-1002.

10. Ahn, C.; Syed, A.; Hu, F.; O'hara, J.A.; Rivera, J.I.; Doi, Y. Microbiological features of KPCproducing Enterobacter isolates identified in a U.S. hospital system. Diagn. Microbiol. Infect. Dis. 2014, 80, 154-158.

11. Andrews J.R.; Ryan E.T. Diagnostics for invasive Salmonella infections: Current challenges and future directions. Vaccine 2015 in press.

12. Qazi, J.I.; Tahir, R. Ocurrence of Amphibacillus and Bacillus endospores in the atmospheric suspended particulate matter of Lahore City. Pakistan J. Zool. 2005, 37, 187-191. 